\title{
Studying Resilient Action Strategies of First Line Managers
}

\author{
Johan Karltun $^{1 *}$, Anette Karltun ${ }^{1}$, Karin Havemose ${ }^{1}$, Magnus Karlsson ${ }^{1,}$ Sofia Kjellström ${ }^{2}$ \\ ${ }^{1}$ Department of Supply Chain and Operations Management, School of Engineering, Jönköping \\ University, Box 1026, 55111 Jönköping, Sweden \\ ${ }^{2}$ Jönköping Academy for Improvement of Health and Welfare, School of Health and Welfare, \\ Jönköping University, Box 1026, 55111 Jönköping, Sweden
}

\begin{abstract}
Background: One important key to an organization's long-term competitiveness is the ability of first line managers (FLMs) to handle their role as a leader in daily work. FLMs main task is to contribute to a high and stable production output according to customer demands from an input that is characterized by instability and variability. To do so, FLMs must develop resilient action strategies - ways of working and daily problem solving that systematically facilitate to cope with instability. In this study protocol we present a methodological approach developed to evaluate and improve these.

Methods/Design: The research approach is collaborative and developmental and performed together with two companies. The approach integrates and extends the theory and application of a model on interactive research and a framework on activity analysis. It will be applied using data collection techniques like interviews, diaries, observations, document analysis, and questionnaires. The analysis and development stages will be performed both separate and in collaboration in workshops and the result is planned to end up in the joint writing of a generic handbook on advantageous action strategies for FLMs'.
\end{abstract}

Discussion: This study contributes with a new integration of two methodological approaches which provides a novel way to understand and develop dynamic on-the-job behaviour in work settings.

Keywords: variability; coping; activity analysis; collaborative research; interactive research; manufacturing industry

\section{Background}

First line managers (FLMs) hold a key function in organizations' long-term competitiveness in terms of their ability to handle the role as leaders in daily work. In manufacturing industry, this should be done in such a way that it provides stable output according to customer demands from an input of material and resources that often are characterized by short term disturbances, variability, different role expectations, goal conflicts, and chaos (Tengblad, 2012). Here we focus on blue collar workers' FLMs, who in their role as FLMs have a lot of conflicting objectives to manage, for example, regarding available resources, subordinates' views versus superiors', centralized and/or local control,

* Correspondence to Department of Supply Chain and Operations Management, School of Engineering, Jönköping University, Box 1026, 55111 Jönköping, Sweden. Email: Johan.Karltun@ju.se

Social Science Protocols, February 2021, 1-15.

http://dx.doi.org/10.7565/ssp.v4.5293 
optimization of cost and capability (quality and delivery). At the operational level of detail, FLMs have to balance daily deliveries in relation to development activities, i.e., technical development, product development, implementation of new system and management concepts (McKay \& Wiers, 2004). These tasks should be performed in a context which cannot be characterized as stable but constantly changing and subject to variability and disturbances (Bakker, Demerouti, \& Verbeke, 2004; Rabey, 2008; Tengblad, 2012). In order to do so in a sustainable way, the FLMs have to develop action strategies about ways of working and problem solving that systematically facilitate coping with the situation. We call this resilient action strategies, which relates to the capability of FLMs to manage the situation including everything that does not occur as planned during a work period, see Figure 1.

Figure 1. First line manager's resilient action strategies in production systems.

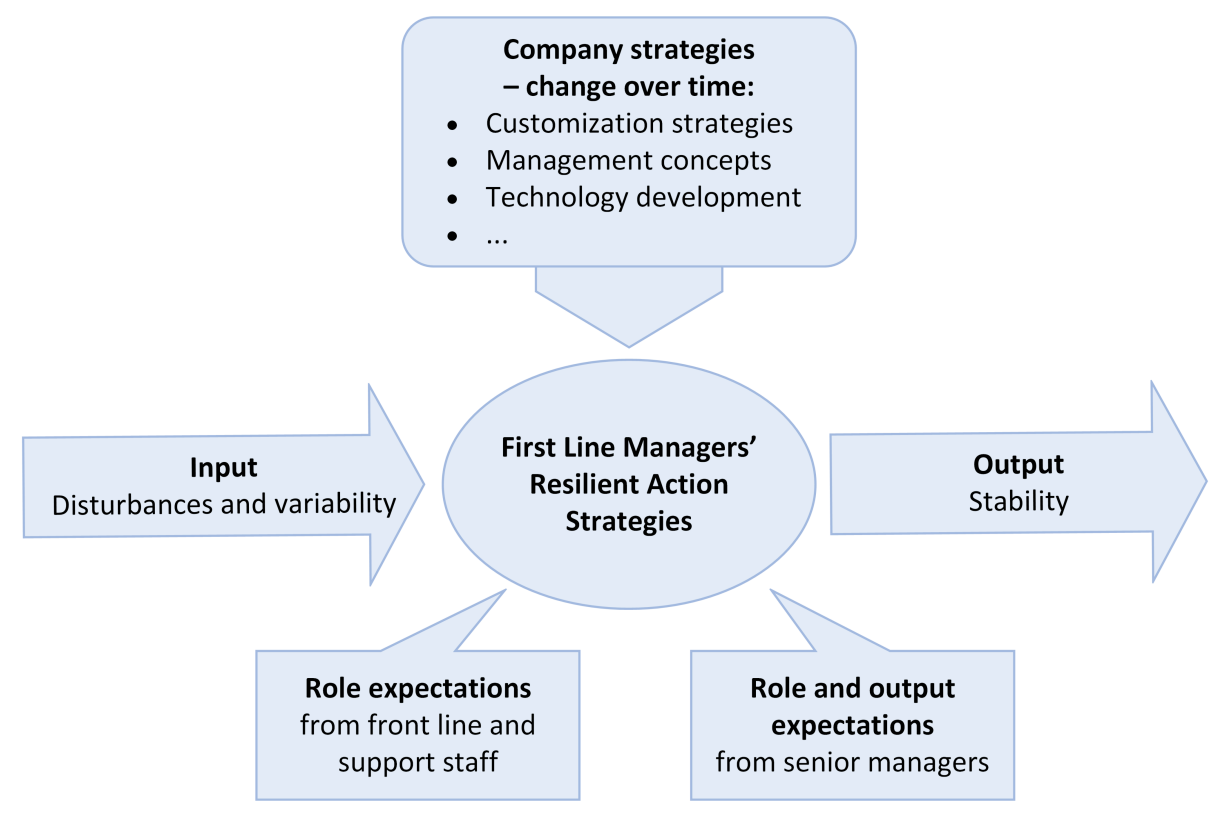

\subsection{The role of FLM}

In a manufacturing industry the FLM plays a key role in the interface between the top management, the techno-structure and the operative core. The FLM is "the manager of the middle line" who incorporate standards from the techno-structure, handles disturbances in the operating core and aggregate feedback information both up and down in the hierarchy and sideways in the operative flow (Mintzberg, 1983). On the shop floor level, FLM's daily work is characterized by complexity, conflicting goals, intense pressure to perform (deliver) and a high level of social interaction with subordinates (Delbridge \& Lowe, 1997). Scherer (1998) describes shop floor control as decision-making in a socio-technical environment where constantly conflicting objectives regarding cost, output and personnel must be dealt with. McKay and Wiers (2004) describe shop floor control in manufacturing as being chaotic and characterized by instability, unforeseen problems to deal with, problematic to handle by formal techniques, and constantly needing human judgment and decision making in at least $95 \%$ of all businesses. All these tasks of the middle line manager require personal contacts. Like the squirrel "Ratatosk", the herald in the mythical tree "Yggdrasil", the FLM is a 
significant communication link and coordinator between the different parts of the organisation.

In industrial activities FLMs operate in a complex system where different planning horizons meet and are in motion. On the shopfloor, where the FLM operates, the long-term strategic planning transforms into daily operational practice. In these processes the FLM has a key position and role as a linking point. In fact, both research and experience show that the different processes are closely linked. "In reality, the strategic management of any operation cannot be separated from how resources and processes are managed at a detailed day-to-day level" (Slack \& Lewis, 2017, p. 262). Therefore, the project focuses on FLMs, who are the individuals who have a management position in a hierarchy closest to the production where the value-adding processes occur, the shopfloor level.

After this brief introduction to the project's overall logic, we can sum up some key factors that FLMs depend on to be able to fulfil their role over time:

- Understanding the expectations and the conditions provided by decisions made by others and/or at higher levels in the organisation (Purcell \& Hutchinson, 2007).

- Being able to interpret information and communicate both upwards, downwards and sideways in a complex system (Mintzberg, 1983).

- Being able to balance conflicting needs, interests and goals between different parts of the system (Delbridge \& Lowe, 1997).

- Take action and navigate in an ever-changing and chaotic environment (Argyris, 2000; McKay \& Wiers, 2004).

- Being able to change leadership-style due to different situations and needs (Hersey \& Blanchard, 1988).

- Have a high degree of stress resistance (Tengblad, 2012).

Knowledge gaps in the role and work of FLMs have been identified by several authors. Tengblad (2012) stress the importance of further research on how management practices are performed in everyday work and what their outcomes are. Yukl (2012) also point out that more research is needed where managers' behaviours can be related to the situation in which they are relevant - e.g., timing and amount.

In this project, we have identified three major knowledge gaps, see Figure 2, where the third is directly linked to the previous two:

1. FLMs' role and daily work in today's industrial context.

2. Dynamic resilient strategies enacted at operational level by FLMs.

3. How FLMs can develop their daily action strategies into even more resilience.

Figure 2. The identified knowledge gaps relating to research focus.

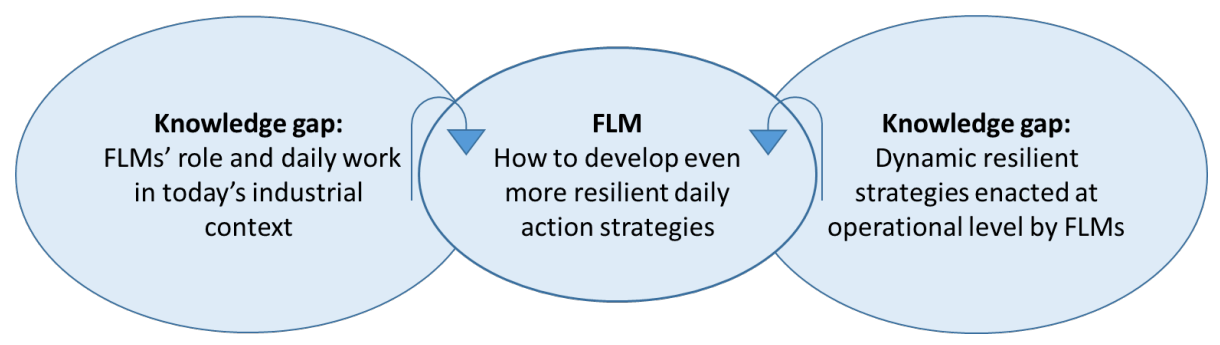

The aim of the overall research project is to co-produce knowledge of how the role of FLMs are enacted in daily work and how FLMs can develop even more resilient action strategies.

We use the resilience concept as the capability of FLMs to apply appropriate action strategies when things do not occur as planned during a work period. In their literature review 
of organisational resilience, (Annarelli \& Nonino, 2016, p. 3) define it as "the organization's capability to face disruptions and unexpected events in advance thanks to the strategic awareness and a linked operational management of internal and external shocks". SullivanTaylor \& Branicki (2011) conclude that SMEs have both a distinctive perspective and approach to resilience when compared to larger organizations. They found that small firms were less concerned with formal systems and its proactive decision-making processes but were rather prepared to take action and 'muddling through' disturbances in daily action. The lack of shared vocabulary for managers to discuss their resilience practice poses a challenge in this area.

The concept action strategies are based on the theory/assumption that every actor designs actions according to believed cause-effect relationships and that these should be observed in order to explain the actions (Argyris, 2000). Berglund \& Karltun (2007) describe how such actions in production management could involve both breaking the rules and creating greater decision latitude than formally decided to cope with the task. Sometimes the concept of 'doing leadership' is used to describe the daily work of leading, where activities are manifested in small talk, management dialogues with individuals and activities taking place during formal and informal meetings (Alvesson \& Sveningsson, 2003; Tyrstrup, 2005; Vänje \& Brännmark, 2017). All such activities can be considered to be action strategies, i.e., actions performed to reach a certain goal or output. However, literature that explicitly focus on FLMs is not that large and there is little written primarily focusing on FLMs' action strategies and how they can be developed towards more resilience in daily work. The focus in this project is thus on dynamics within single organisations related to the action strategies of FLMs and linked to the demands for output, both regarding deliveries and development. We also emphasize that "resilience is a dynamic process of steering and not a static state of an organization" (Hale \& Heijer, 2017, p. 37).

\subsection{Aims}

The aim of this study protocol is to detail a planned methodology on how a collaborative interactive research approach is used to develop academic knowledge and action in participating companies regarding resilient action strategies for first line managers. This is done by integrating one model for interactive research with a framework for intervention of work systems using activity analysis.

\section{Methods/Design}

The section is organized as follows. First, we introduce the arguments for the collaborative research design chosen, thereafter the participating companies and their formal involvement in the collaboration are described. Then we outline how the model for interactive research and framework for activity analysis are integrated to specify the planned research and development process design that are supposed to bring the results aimed for.

\subsection{A collaborative research design}

The research approach is based on close collaboration with companies, and we have chosen an interactive design where theory development in academia and practices in participating companies evolve iteratively but also according to the demands in the contexts respectively (Aagaard Nielsen \& Svensson, 2006; Svensson, Ellström, \& Brulin, 2007). This means that knowledge development occurs through a common platform for researcher/ practitioner collaboration, see Figure 3. 
Figure 3. The interaction between the 'research system' and the 'practice system' in interactive research. Modified from Ellström et al. (1999).

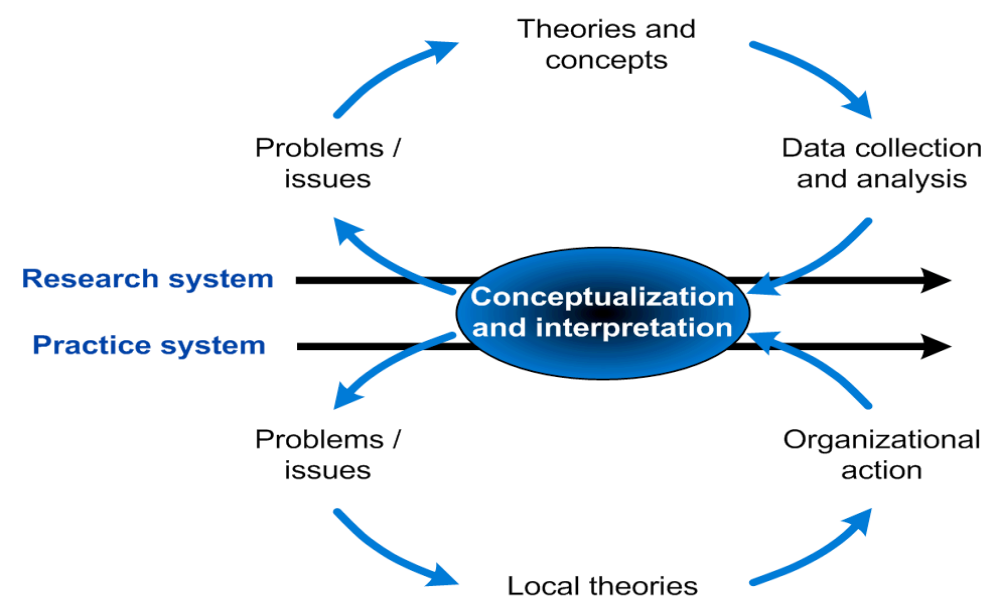

Interactive research has the potential to bridge the gaps between theory and practice, addressing for example the knowledge transfer problem, which refers to translating and diffusing research knowledge into practice (Van de Ven, 2007). Moreover, engaging others whose perspectives are relevant to a complex phenomenon, can increase the likelihood of advancing fundamental knowledge (Van de Ven \& Johnson, 2006). This can be addressed through the means of the collaborative relationship between researchers and practitioners, which also could mean better access to valid data compared to traditional research (Argyris, 1980; Nyström, Karltun, Keller, \& Andersson Gäre, 2018). The interactive design described here is further built on the assumptions that to understand the dynamics in real life settings it is important to examine contextual factors and expectations affecting daily work (Figure 1).

A partnership between scholars and practitioners is strived for in order to co-produce results that cannot only be described by "what is" but also by "how to," implying that the knowledge created should be actionable (Pettigrew, Woodman, \& Cameron, 2001). Such a research approach places demands on the researcher to understand and process various situations and perspectives, communicate with a lot of actors, support the participants own learning and have a communicative competence (Johansson \& Wallo, 2019). It also requires of the practitioners to be active partners in development and learning throughout the process (Westlander, 2000). Interactive research further stresses the joint learning that goes on between the company participants and the researchers throughout the entire research process - from the definition of the problem to the analysis and the dissemination of the results (Aagaard Nielsen \& Svensson, 2006). Taking these aspects into consideration, an interactive multiple case study approach including two different companies, using data triangulation is applied to fulfill the aim of the study (Yin, 2018).

\subsection{Participating companies}

Two manufacturing companies are participating in the project, a Lighting company and a Truck company.

The Lighting company develops, produces and market professional lighting solutions for public environments. The participating factory site has about 600 employees, they have 8 FLMs, and each of them is responsible for 40-45 employees. A main challenge for the role of FLMs is their exposed intermediate position between workers, technical support staff and 
higher management. The Lighting company also want to clarify, strengthen and further develop FLMs' role and what FLMs are expected to do in shop floor management.

The Truck company produces cabs for trucks in Europe. The participating factory site has 2700 employees. They have about 100 FLMs and each of them is responsible for 12-25 subordinates. The main challenge for the FLMs in this company is related to strategic changes towards a safety culture, providing the highest quality and launching of a long-term competitive productivity roadmap. Major components in these efforts are leadership system, attitude and strategy. The FLMs are considered key players in this leadership and lean model development.

\subsection{Letters of intent}

Company contacts will be established early in the project building phase, followed up with personal meetings with both top-managers and FLM's. The final formalization of the participation in the project is made when the company's project contact person signs the agreement in the "Company Letter-of-intent (LoI)". The LoI regulates the company's contribution to the project such as: internal resources, motivation in taking part in the project, industrial relevance, forms for co-production, expected co-produced results, knowledge transfer, utilizing of the results and information dissemination. The LoI also regulates confidentiality, publishing issues and ethical requirements for participation.

\subsection{Ethics}

In this type of collaborative explorative study, no formal ethical approvement from the university or independent body is required but all procedures are aligned with and will follow the Swedish Law (Ministry of Education, 2003). An informed consent process will be performed. All participants that will have an active role will be provided written information by e-mail but also oral information when meeting the researchers. The information includes information about the study, conditions for participations and ethical issues like voluntariness, right to withdrawal and confidentiality. The informed consent process for the interviews begins by each person receiving an e-mail with information, which is repeated in the face-to-face interviews. Verbal consent will be obtained from the participants after the information is given at the interview. They consent to that the data will be used for research purpose and will be informed that all data would be treated with confidentiality.

\subsection{Research intervention model}

To elucidate the characteristics of FLMs' work, an approach inspired by activity analysis (Guérin, Laville, Daniellou, Duraffourg, \& Kerguelen, 2007) is used to guide the research process, see Figure 4. 
Figure 4. Framework for the study of first line managers' (FLMs') work, inspired and modified from Guérin et al. (2007).

\begin{tabular}{|c|c|c|c|}
\hline & $\begin{array}{l}\text { Establishing activity } \\
\text { perspective }\end{array}$ & $\begin{array}{l}\text { Identifying various } \\
\text { perspectives on work }\end{array}$ & $\begin{array}{c}\text { Favouring different } \\
\text { perspectives }\end{array}$ \\
\hline \multirow[t]{2}{*}{$\begin{array}{l}\text { Defining } \\
\text { the focus }\end{array}$} & $\begin{array}{l}\text { 1) } \\
\text { Define } \\
\text { difficulties and } \\
\text { opportunities for } \\
\text { FLMs and how they } \\
\text { are expressed }\end{array}$ & $\begin{array}{l}\text { 2) } \\
\text { Identify how activity } \\
\text { (converge/diverge) } \\
\text { functions together } \\
\text { with other activities in } \\
\text { the company }\end{array}$ & $\begin{array}{l}\text { 3) } \\
\text { Setup conditions } \\
\text { (ethical, social, } \\
\text { institutional) for } \\
\text { different perspectives }\end{array}$ \\
\hline & $\begin{array}{l}\text { Object of } \\
\text { intervention }\end{array}$ & $\begin{array}{l}\text { Position of } \\
\text { intervention }\end{array}$ & $\begin{array}{l}\text { Condition of } \\
\text { intervention }\end{array}$ \\
\hline $\begin{array}{l}\text { Making a } \\
\text { diagnosis }\end{array}$ & $\begin{array}{l}\text { 4) } \\
\text { Deepening the } \\
\text { knowledge } \\
\text { about work activity }\end{array}$ & $\begin{array}{l}\text { 5) Understanding } \\
\text { the functioning } \\
\text { of the company from } \\
\text { activity perspective }\end{array}$ & \begin{tabular}{|l} 
Confronting \\
representations \\
of the company in \\
terms of work \\
(status, project) \\
FLMs' \\
resilient \\
action \\
strategies
\end{tabular} \\
\hline \multirow[t]{2}{*}{$\begin{array}{l}\text { Defining } \\
\text { objectives } \\
\text { of action }\end{array}$} & $\begin{array}{l}\text { 7) } \\
\text { Improvement list } \\
\text { of requirements } \\
\text { for change } \\
\text { (design, layout, } \\
\text { training, organization) }\end{array}$ & $\begin{array}{l}\text { 8) } \\
\text { Considering work as } \\
\text { strategic variable } \\
\text { (process of design, } \\
\text { decision and } \\
\text { consultations) }\end{array}$ & $\begin{array}{l}\text { 9) } \\
\text { Increasing room for } \\
\text { manoeuvre } \\
\text { and negotiating } \\
\text { trade-offs } \\
\text { (redefining objectives) }\end{array}$ \\
\hline & $\begin{array}{l}\text { Results of } \\
\text { intervention }\end{array}$ & $\begin{array}{l}\text { Effects of } \\
\text { intervention }\end{array}$ & $\begin{array}{l}\text { Challenges of } \\
\text { intervention }\end{array}$ \\
\hline
\end{tabular}

Based on the nine parts in this three-level grid figure, three different phases and activities of the research process are described below numbered 1-9.

\subsection{Defining the focus - phase I}

Defining the focus is divided into 1) Object, 2) Position and 3) Condition of intervention, see Figure 5.

Figure 5. Framework for defining the focus.

\begin{tabular}{|c|c|c|c|}
\hline & $\begin{array}{c}\text { Establishing activity } \\
\text { perspective }\end{array}$ & $\begin{array}{l}\text { Identifying various } \\
\text { perspectives on work }\end{array}$ & $\begin{array}{l}\text { Favouring different } \\
\text { perspectives }\end{array}$ \\
\hline $\begin{array}{l}\text { Defining } \\
\text { the focus }\end{array}$ & $\begin{array}{l}\text { 1) } \\
\text { Define } \\
\text { difficulties and } \\
\text { opportunities for } \\
\text { FLMs and how they } \\
\text { are expressed }\end{array}$ & $\begin{array}{l}\text { 2) } \\
\text { Identify how activity } \\
\text { (converge/diverge) } \\
\text { functions together } \\
\text { with other activities in } \\
\text { the company }\end{array}$ & $\begin{array}{l}\text { 3) } \\
\text { Setup conditions } \\
\text { (ethical, social, } \\
\text { institutional) for } \\
\text { different perspectives }\end{array}$ \\
\hline & $\begin{array}{l}\text { Object of } \\
\text { intervention }\end{array}$ & $\begin{array}{l}\text { Position of } \\
\text { intervention }\end{array}$ & $\begin{array}{l}\text { Condition of } \\
\text { intervention }\end{array}$ \\
\hline
\end{tabular}


The initialisation of the research process commences with defining the focus of the work intended and the knowledge base for the approach. It is a joint endeavour involving researchers and participating companies. This was done before the application for research grants and it was in this case a process over time including several contacts with and visits at different companies, collecting numerous different opinions on how the approach should be focused and formulated. The result of this process is the definition of the focus of intervention and the research grant application, which in this case are the first line managers' action strategies and their working conditions for supporting a stable production output. In this stage the object of intervention (1) was defined as FLMs' strategical, crucial and difficult role in the practice system and how it is enacted in their action strategies and a corresponding research interest in the research system.

The position of the intervention (2) is based on existing literature, companies' and researchers' experiences and organizing of FLMs. During the setup of the project this has been an issue that was intensely discussed by researchers and practitioners in order to set a common base. The result of these discussions is shown as the expectations regarding FLMs' role in the production system as pictured in Figure 1.

The condition of the intervention (3) is built on existing research gaps and companies' knowledge request on improvement regarding the work of FLMs as stated in letters of intent formulated by participating companies. These include the goals for participating formulated by the companies themselves as well as their willingness to spend specified time in the project and the overall content of these letters is specified in section 2.3 above. It also includes an agreement on following the timeline in the project, collaboration procedures involved and access to companies' workshops and personnel.

After received grant, an adaptation of the focus is further developed during the initial phase of the research together with involved companies. In this stage the companies are expected to within their organizations also develop their own project group, their own motivation for participating and their own goals regarding the results and effects of participating in the project. The entire results of these activities are processed in a first workshop where participating companies' project groups as well as the group of researchers learn to know each other in more depth, present their way of creating conditions for the project and their refined specified goals with participating. The process is further anchored with the higher management of each participating company. This process after receiving the grant is a repetition of defining the focus, an additional refinement and serve as a base for the development of, and collaboration in, the project.

Using the interactive research model for describing this phase will result in a combination of processes as depicted in Figure 6. The research system is defining the focus in a process of identifying research interests, closing research gaps and contribute to the focus regarding the need for updated or new knowledge from a theoretical point of view. The practice system is defining the focus in a process of realizing the potential value of improved functioning of first line managers and addressing this in a knowledge and improvement request. The overall result of this process is the agreed-on focus being more resilient action strategies of FLMs, i.e., how they solve problems during daily work and activities involved in this. 
Figure 6. Interactively defining the focus.

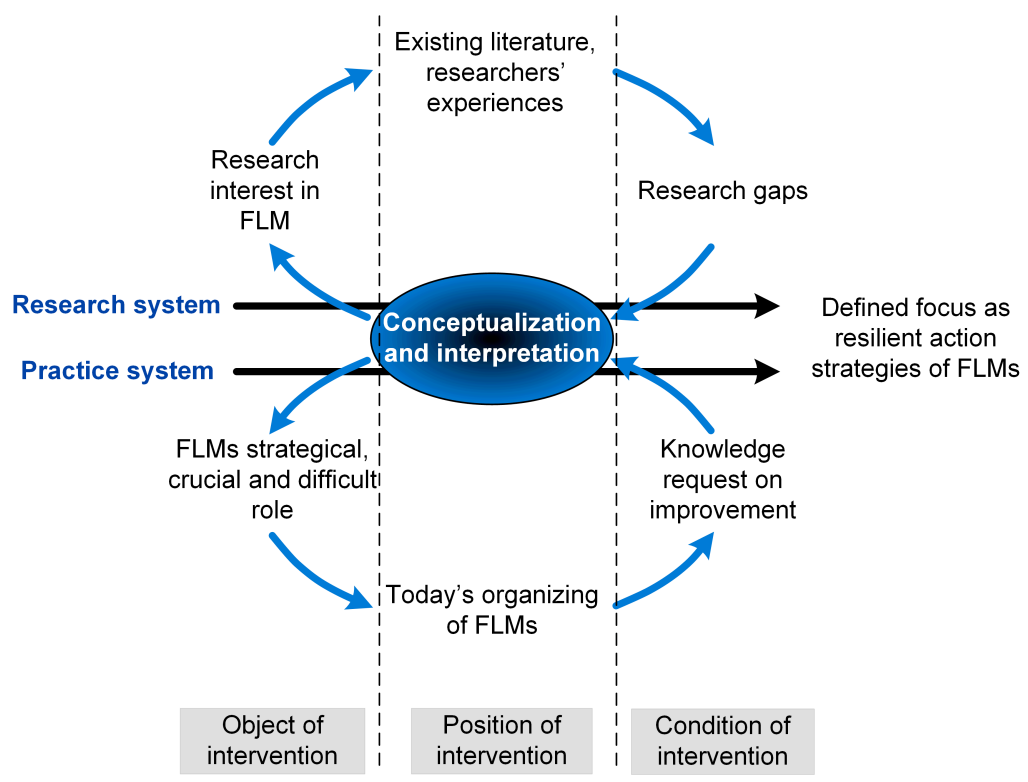

\subsection{Making a diagnosis - phase II}

Making a diagnosis is divided into 4) Deepening the knowledge about work activity, 5) Understanding the functioning of the company from an activity perspective and 6) Confronting representations of the company (see Figure 7).

Figure 7. Framework for making a diagnosis/

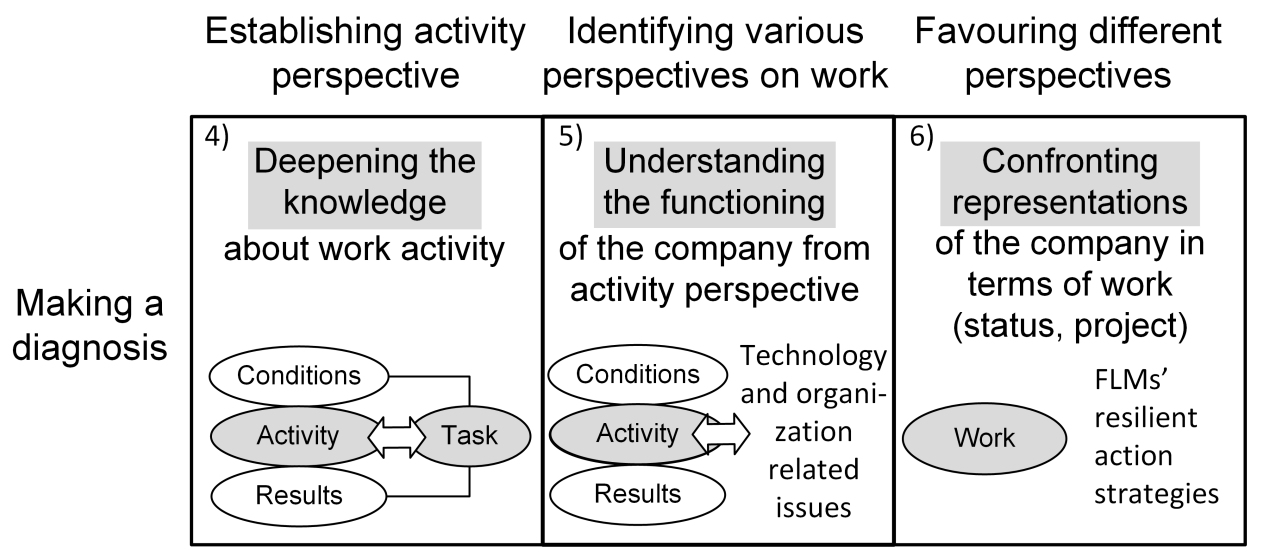

The research approach includes an in-depth investigation of the workplace, work situation and working conditions that set the context and content of what can be called FLMs' formal work. When diagnosing how the formal work is performed, issues related to the individual as well as the variabilities of the work settings and the individuals are acknowledged. The work must also be broken down to identifiable tasks and activities. Deepening the knowledge about work activity (4) involves two main strands of investigation. One is related to the theoretical foundation of the research and involves deepened literature review bringing forward what is known and considered important regarding the focus. The other strand includes examining the work activities from the perspective of the FLMs through primary data collection using different techniques in order to bring knowledge both regarding conscious and less conscious 
aspects of FLMs' work activities. This will be done through semi-structured interviews, recorded diaries, observations, and shadowing and thereby combining FLMs own narratives with data collected by researchers involved.

Understanding the functioning of the company from an activity perspective (5) includes providing a rich picture of the context of FLMs' work activities. It concerns how the activities studied are affected by the characteristics of the organizational and technical context where they are enacted. This is achieved by using several different data collection techniques, generating both quantitative and qualitative data, including interviews with surrounding members of the organization such as subordinate positions like workers and team leaders, service functions like quality officers, maintenance and technical staff, human relations officers and schedulers as well as superordinate positions like work shop managers and production managers. Moreover, document studies of formal requirements, role descriptions, routine descriptions, process charts, observations, etc. will be done.

Confronting representations (6) of the company in dialogue is a process of describing and elucidating the work using different perspectives based on analysis of data. This is dependent on an open dialogue within the company as well as between the researchers and the company participants. Such dialogues will contribute to develop knowledge about work activities, contextual conditions and interactions to develop more resilient action strategies for FLMs. This will be implemented by iterative workshops by involving FLMs but also team leaders', department managers' and various support functions. By mixing multiple views and expectations of work, theoretical aspects, and conflicts, it will be possible to enhance and deepen the diagnosis.

One of the overall important aspects of making a diagnosis is to produce data that is actionable, which means it has a character that makes it possible to use for producing ideas and actions for change. Revealing relationships, system effects and dependencies are of high importance during the diagnosis, always using the activity perspective. The diagnosis phase is further represented in the second loop in the interactive model (see Figure 8).

Figure 8. Interactively making an activity- and context-based diagnosis

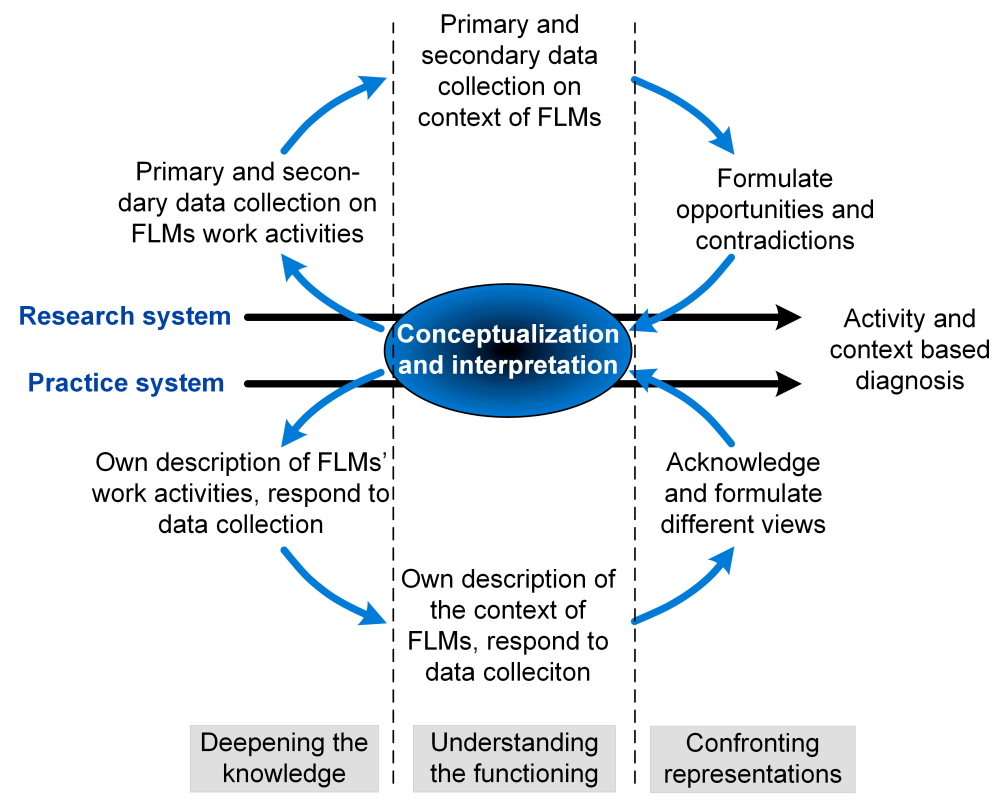

Social Science Protocols, February 2021, 1-15. 


\subsection{Defining objectives of action - phase III}

Objectives of action are divided into 7) Results, 8) Effects, and 9) Challenges of the intervention (see Figure 9).

Figure 9. Framework for defining objectives of action

\begin{tabular}{|c|c|c|c|}
\hline & $\begin{array}{c}\text { Establishing } \\
\text { activity } \\
\text { perspective }\end{array}$ & $\begin{array}{l}\text { Identifying } \\
\text { various } \\
\text { perspectives } \\
\text { on work }\end{array}$ & $\begin{array}{c}\text { Favouring } \\
\text { different } \\
\text { perspectives }\end{array}$ \\
\hline \multirow{3}{*}{$\begin{array}{c}\text { Defining } \\
\text { objectives of } \\
\text { action }\end{array}$} & 7) & 8) & 9) \\
\hline & $\begin{array}{l}\text { Improvement list } \\
\text { of requirements } \\
\text { for change } \\
\text { (design, layout, } \\
\text { training, } \\
\text { organization) }\end{array}$ & $\begin{array}{l}\text { Considering work } \\
\text { as strategic } \\
\text { variable } \\
\text { (process of } \\
\text { design, decision } \\
\text { and consultations) }\end{array}$ & $\begin{array}{l}\text { Increasing room } \\
\text { for manoeuvre } \\
\text { and negotiating } \\
\text { trade-offs } \\
\text { (redefining } \\
\text { objectives) }\end{array}$ \\
\hline & $\begin{array}{l}\text { Results of } \\
\text { intervention }\end{array}$ & $\begin{array}{l}\text { Effects of } \\
\text { intervention }\end{array}$ & $\begin{array}{l}\text { Challenges of } \\
\text { intervention }\end{array}$ \\
\hline
\end{tabular}

The results of intervention (7) relate to an improvement list of requirements to improve FLMs' action strategies. With action strategies in focus, the results are expected to relate to interactions with the contextual organization and technology. However, the diagnosis in phase II is expected to reveal a broad range of results that can be addressed in order to present requirements to improve FLMs' action strategies.

The effects of the intervention (8) are expected to be twofold. First, the awareness of the contextual conditions for FLMs will increase just by companies' participating in the project and the focus used. This will by itself induce adjustments and changed behaviours among participating personnel. Secondly, increased understanding of how to implement appropriate measures to improve FLMs' action strategies can release the formulation of necessary investments in redesign, decisions on chosen aspects and strategies for implementing work improvements.

The challenges of the intervention (9) are associated with the fact that FLMs can be seen as the communication and organizational interaction hubs closest to the shopfloor. As such they do have a lot of dependencies on and interactions with workers and managers at different levels and in different positions in the company. Changing the way of working and the contextual conditions for FLMs' activities will thus influence many different people, patterns of communication and interactions and create constraints or conflicts with other priorities in the production system. By definition it will thus redefine objectives, make negotiations of trade-offs necessary to increase the room for manoeuvre for FLMs.

This third phase is depicted in the third loop in the interactive model (see Figure 10). 
Figure 10. Interactively defining and negotiating the objectives of action.

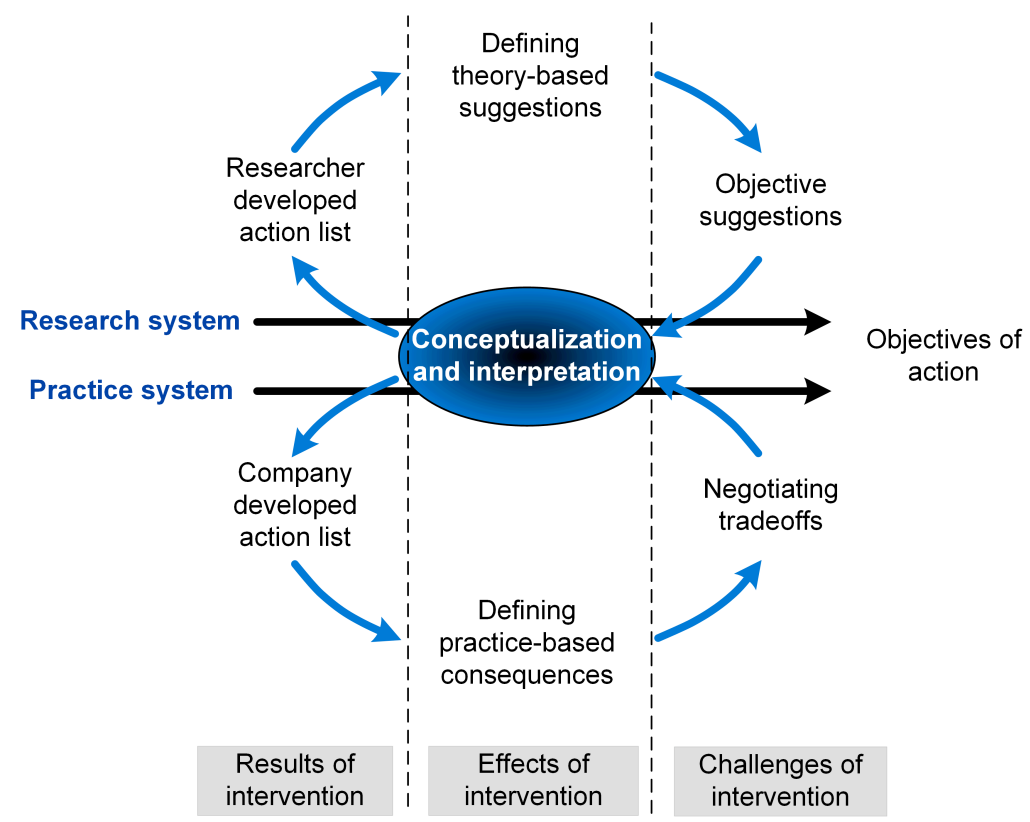

The resulting objectives of action and the documentation thereof will thus be achieved by companies and researchers developing action plans based on the earlier phases, using multiple perspectives on work and identifying and meeting the challenges in using several perspectives. The collaborative work that is expected to create the planned result will be undertaken in workshops with researchers' and each company separately as well as common workshops with both companies to openly discuss and develop these objectives and action plans for implementation. The documentary result will be a co-produced handbook for developing resilient action strategies for FLMs in a more generic/principal sense as well as scientific publications. Other results that are expected is changes in the ways companies organize and interact around FLMs as well as changes in the way the activities of the FLMs are enacted, that is the action strategies of the involved FLMs.

\section{Discussion}

This study aims to develop a methodology for increasing academic knowledge and change in participating companies regarding how first line managers' can develop resilient action strategies in their daily work that systematically facilitate to cope with instability. It brings together the concepts of resilience and action strategies in the light of the contextual conditions in each company and how these conditions affect working conditions for FLMs to support a stable production output.

Resilience in itself has become a widely used word related to several research concepts and ideas spanning over several subjects. It must be emphasized that we are here interested in the organisational resilience and how it can be designed into daily operations and individual ways of doing work. The personal resilience that is attributed to personal traits (Crane, 2017) is very close but will not be studied, but instead the more general behaviour expected and performed related to the role of a FLM. One of the issues that needs to be further developed during the process is then how to characterize and distinguish identifiable features that can be connected to organizational resilience related to FLMs and their way of relating appropriate action strategies to cope with instability in their respective context. Only having two 
companies in the study will delimit the research results to some extent but the aim is regardless to end up in some general conclusions regarding resilient action strategies and appropriate reasoning on how to develop such strategies.

In addition to deep knowledge of each of these concepts, it involves understanding how people's on-the-job behaviours are affected by the real work setting in terms of organizational and technical features and one of the models we use for that was formulated by Porras \& Robertson (1992). This requires knowledge of the dynamics in real work settings which calls for an in-depth study in collaboration with companies. The interactive research approach elaborated on in this study protocol is built on the assumptions that to understand these dynamics and develop actionable knowledge in practice, it is also necessary to examine real contextual factors and expectations and to be able to distinguish between work as prescribed and work as done. This is closely related to the activities performed in daily work and a core issue in activity analysis.

It is furthermore essential to understand the functioning of the company from an activity analysis perspective (Guérin et al., 2007) and how it affects the production outcome in order to improve FLMs' resilient action strategies. This requires a close interactive research collaboration with the participating companies (Ellström et al., 1999). The interactive research approach makes use of the process view of change and the idea that the intervention regarding change of on-the-job behaviour immediately starts when there is any communication established (Schein, 1988). The organizing of project groups in both participating companies thereby anchors the knowledge development and the change process in both companies' project groups. The interaction between the research and practice systems will follow a dynamic process of knowledge development, characterized by iterations and unforeseen changes. It is a collaboration between two systems that are constantly moving in separate development processes (Nyström et al., 2018).

The novel feature of this study is the combining, elaborating and adapting a model for interactive research with a framework for activity analysis. The result is a more specified development approach, which we further propose can be used more generically to explore and understand behavioural and dynamic contextual work settings in various work systems. The integration of the two approaches helped the researchers to clarify how the interaction processes involved can be orchestrated and how the collaboration between the research system and the practice system can be managed. It is necessary to handle the dynamics involved, which might be one of the driving forces in the collaboration, but at the same time it is also a resilience challenge.

\section{Declarations}

Acknowledgements: We wish to thank the companies and their involvement for the collaboration in the research grant application process.

Funding: This work was supported by Jönköping University and the Swedish Knowledge Foundation, grant no 20180190. The Knowledge Foundation management placed no restrictions and had no influence on the results.

Competing interests: The authors declare that they have no competing interests. 


\section{References}

Aagaard Nielsen, K., \& Svensson, L. (2006). Action and interactive research: beyond practice and theory. Shaker Publishing.

Alvesson, M., \& Sveningsson, S. (2003). Managers doing leadership: The extraordinarization of the mundane. Human Relations, 56(12), 1435-1459.

Annarelli, A., \& Nonino, F. (2016). Strategic and operational management of organizational resilience: Current state of research and future directions. Omega, 62, 1-18. https://doi.org/https://doi.org/10.1016/j.omega.2015.08.004

Argyris, C. (1980). Inner Contradictions of Rigorous Research. Academic Press.

Argyris, C. (2000). The Relevance of Actionable Knowledge for Breaking the Code. In M. Beer \& N. Nohria (Eds.), Breaking the Code of Change (pp. 415-427). Harvard Business School Press.

Bakker, A. B., Demerouti, E., \& Verbeke, W. (2004). Using the job demands resources model to predict burnout and performance. Human Resource Management, 43(1), 83104. https://doi.org/https://doi.org/10.1002/hrm.20004

Berglund, M., \& Karltun, J. (2007). Human, technological and organizational aspects influencing the production scheduling process. International Journal of Production Economics, 110(1-2), 160-174. https://doi.org/https://doi.org/10.1016/j.ijpe.2007.02.024

Crane, M. F. (2017). Managing for resilience: A practical guide for employee wellbeing and organizational performance. Taylor \& Francis.

Delbridge, R., \& Lowe, J. (1997). Managing human resources for business success: a review of the issues. International Journal of Human Resource Management, 8(6), 857-873. https://doi.org/10.1080/095851997341379

Ellström, P.-E., Eklund, J., Kock, H., Lindström, L., \& Melin, U. (1999, March 16-19). Knowledge Creation Through Collaborative Research: An emerging model HSS -99, Falun.

Guérin, F., Laville, A., Daniellou, F., Duraffourg, J., \& Kerguelen, A. (2007). Understanding and transforming work. The practice of ergonomics. Lyon: Anact Network Edition.

Hale, A., \& Heijer, T. (2017). Defining resilience. In Resilience engineering (pp. 47-52). CRC Press.

Hersey, P., \& Blanchard, K. H. (1988). Management of Organizational Behavior: Utilizing Human Resources. Prentice-Hall. https://books.google.se/books?id=1S5HAAAAMAAJ

Johansson, P. E., \& Wallo, A. (2019). Exploring the work and competence of interactive researchers. Journal of Manufacturing Technology Management. https://doi.org/https://doi.org/10.1108/JMTM-09-2018-0307

McKay, K. N., \& Wiers, V. C. S. (2004). Practical Production Control: a survival guide for planners and schedulers. J. Ross Publishing, Inc.

Law on ethic approval of research involvning humans, (2003).

Mintzberg, H. (1983). Structure in Fives: Designing Effective Organizations. Prentice-Hall.

Nyström, M. E., Karltun, J., Keller, C., \& Andersson Gäre, B. (2018). Collaborative and partnership research for improvement of health and social services: researcher's experiences from 20 projects. Health research policy and systems, 16(1), 1-17. https://doi.org/https://doi.org/10.1186/s12961-018-0322-0

Pettigrew, A. M., Woodman, R. W., \& Cameron, K. S. (2001). Studying organizational change and development: Challenges for future research. Academy of management journal, 44(4), 697-713. https://doi.org/https://doi.org/10.5465/3069411 
Porras, J. I., \& Robertson, P. J. (1992). Organizational Development: Theory, Practice, and Research. In M. D. Dunette \& L. M. Hough (Eds.), Handbook of industrial and organizational psychology (Vol. 3, pp. 719-822). Consulting Psychologists Press.

Purcell, J., \& Hutchinson, S. (2007). Front line managers as agents in the HRM performance causal chain: theory, analysis and evidence. Human Resource Management Journal, 17(1), 3-20. https://doi.org/https://doi.org/10.1111/j.1748-8583.2007.00022.x

Rabey, G. (2008). The potential of the frontline manager. Industrial and Commercial Training, 40(3), 156-161. https://doi.org/ https://doiorg.proxy.library.ju.se/10.1108/00197850810868667

Schein, E. H. (1988). Process Consultation - Its Role in Organisation Development (2 ed., Vol. I). Addison-Wesley Publishing Company.

Scherer, E. (Ed.). (1998). Shop floor control - a systems perspective. Springer.

Slack, N., \& Lewis, M. (2017). Operations Strategy (Fifth ed.). Pearson.

Sullivan-Taylor, B., \& Branicki, L. (2011). Creating resilient SMEs: why one size might not fit all. International Journal of Production Research, 49(18), 5565-5579. https://doi.org/https://doi.org/10.1080/00207543.2011.563837

Svensson, L., Ellström, P.-E., \& Brulin, G. (2007). Introduction-on interactive research. International journal of action research, 3(3), 233-249.

Tengblad, S. (2012). The work of managers: Towards a practice theory of management. Oxford University Press.

Tyrstrup, M. (2005). På gränsen till fiasko: om ledarskapets vardag och det improviserande inflytandet. Studentlitteratur.

Van de Ven, A. H. (2007). Engaged scholarship: A guide for organizational and social research. Oxford University Press on Demand.

Van de Ven, A. H., \& Johnson, P. E. (2006). Knowledge for theory and practice. Academy of management review, 31(4), 802-821.

Vänje, A., \& Brännmark, M. (2017). Walking around the pyramids: Managers' shop-floor activities in Lean-inspired organizations. Economic and Industrial Democracy, 38(3), 495-512. https://doi.org/https://doiorg.proxy.library.ju.se/10.1177/0143831X15580351

Westlander, G. (2000). Researcher roles in models of action research. Nordisk psykologi, 52(3), 197-216.

Yin, R. K. (2018). Case Study Research and Applications (Sixth ed.). Sage.

Yukl, G. (2012). Effective Leadership Behaviors: What We Know and What Questions Need More Attention? The Academy of Management Perspectives, 26(4), 66-85. https://doi.org/https://doi.org/10.5465/amp.2012.0088 